\title{
Kadın Azmağı́'nın (Gökova Körfezi-Muğla) Su Kalitesi Yönünden Mevsimsel İncelenmesi
}

\author{
Mustafa DÖNDÜ ${ }^{1}$ (I) Nedim ÖZDEMiR ${ }^{* 2}$ \\ ${ }^{1}$ Muğla Sıtkı Koçman Üniversitesi, Fen Bilimleri Enstitüsü, Su Ürünleri Mühendisliği Anabilim Dalı-Kötekli-Muğla \\ ${ }^{2}$ Muğla Sıtkı Koçman Üniversitesi, Su Ürünleri Fakültesi, Temel Bilimler Bölümü- Kötekli-Muğla
}

Öz: Bu çalışma, Gökova Körfezi'ni besleyen kaynaklardan birisi olan Kadın Azmağı́'nda gerçekleştirilmiştir. Haziran 2012Mayıs 2013 tarihleri arasında Kadın Azmağı'nın stratejik noktalarından seçilmiş 5 istasyondan alınan su numunelerinde bazı fiziko-kimyasal parametre analizleri Muğla Sıtkı Koçman Üniversitesi Su Ürünleri Fakültesi Temel Bilimler Bölümü Laboratuvarı'nda yapılmıştır. Yapılan su analizleri çalışmasında; su sıcaklı̆̆ı $\left(14.71-23.12^{\circ} \mathrm{C}\right), \mathrm{pH}(6.70-8.10)$, elektriksel iletkenlik (3867-46779 $\mathrm{SScm}^{-1}$ ), tuzluluk (\%o3.00-30.90), çözünmüş oksijen (6.14-8.72 $\mathrm{mgl}^{-1}$ ), klorofil-a (0.0085-0.0098 $\mathrm{mg}^{-1}$ ), BOi ${ }_{5}\left(0.68-2.52 \mathrm{mgl}^{-1}\right)$, nitrat azotu $\left(2.03-5.03 \mathrm{mg}^{-1}\right)$, amonyum azotu $\left(0.11-1.03 \mathrm{mgl}^{-1}\right)$ ve orto-fosfat $\left(0.04-0.28 \mathrm{mgl}^{-1}\right)$ olarak ölçülmüştür. Sonuç olarak, mevsimsel bazda Kadın Azmağı'nı kirleten en önemli çevresel faktörlerin turizm ve tarımsal faaliyetler, Azmak boyunca faaliyet gösteren restaurantlar, ikincil olarak konutlar, apartlar, atık sular ve günlük tur tekneleri olarak ortaya konmuştur. Aynı zamanda elde edilen bu fiziko-kimyasal analiz verileri "Kıta İçi Su Kaynakları Kontrolü Yönetmeliği'ne göre de değerlendirilmiştir.

Anahtar Kelimeler: Gökova Körfezi, Kadın Azmağı, su kalitesi, fiziko-kimyasal parametreler, çevresel faktörler

Seasonal Investigation of Water Quality of The Kadın Azmağı Creek (Gökova Bay-Muğla)

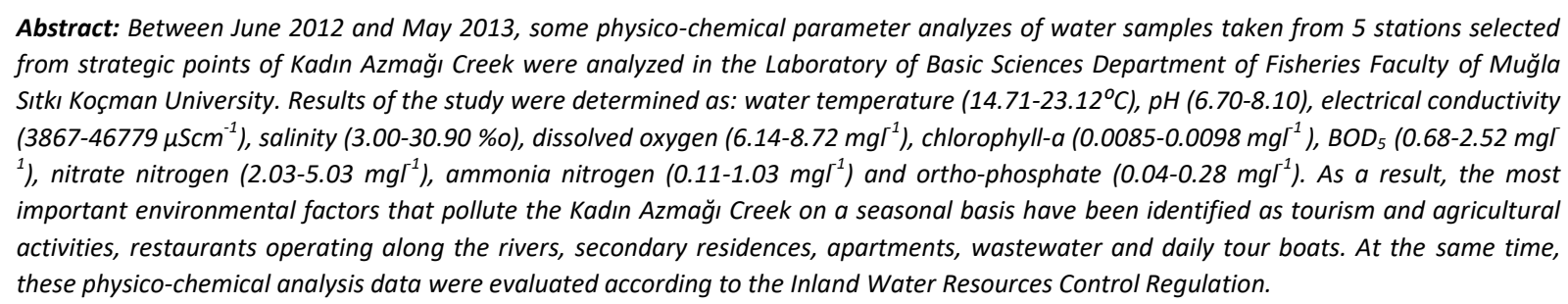

Keywords: Gökova Bay, Kadın Azmağı Creek, water quality, physico-chemical parameters, environmental factors.

\section{GiRiş}

Su kaynaklarının yönetiminde ve geliştirilmesinde yüzeysel su kalitesinin tespit edilmesi, kalitenin kullanılabilir su miktarını sınırlayıcı özelliğinden dolayı önemlidir. Suyun çeşitli amaçlar için kullanımı göz önüne alındığında, kirli su kaynaklarının tüm ekosisteme zarar vereceği açıktır. Bundan dolayı su kalitesinin gözlem yaparak tanımlanması ve kaliteyi en iyi şekilde temsil edecek ölçüm yerlerinin, sıklıklarının, süresinin ve gözlemlenecek su kalitesi değişkenlerinin iyi belirlenmesi gerekir. Günümüzde su kaynaklarının gözlem çalışmalarının sistematik bir yaklaşım ile gerçekleştirilmesi, bu kaynakların optimum yönetimi açısından gerekli hale gelmiştir. Türkiye'de de, bugüne kadar toplanan su kalite verilerinin yeterliliği ve mevcut ölçüm sistemleri artık sorgulanmaktadır (Gündoğdu ve Özkan, 2006).

Kadın Azmağı, denizel bölge içerisinde bulunan Gökova Körfezi ile su girişlerinin bulunduğu bir tatlısu bölgesidir. Gökova Körfezi turistler için cazip doğal çevresel dokusu mevcut balık yatakları ile balıkçılığın geliştiği potansiyeli yüksek bir yerdir. Gökova Körfezi'nin tarihi ve doğal güzelliklerinin yanı sıra, bir turizm merkezi oluşu, Azmağa ulaşan bir kirlilik unsurunun olup olmayışının seçilen 5 istasyonda araştırılmış ve bölgenin gelecek nesiller için korunup, sürdürülebilirliğinin devamı açısından bu çalışma yapılmıştır.

\section{MATERYAL VE YÖNTEM}

Araştırma Alanının Tanıtılması

Gökova Körfezi Ege Denizi ile Akdeniz'in birleştiği bölgenin bir kıyısına kurulmuş (Şekil 1), Muğla İli, Ula İlçesine bağlı bir yerleşim yeridir. Kışları kendi halinde sakin bir belde olan Akyaka, yaz sezonunda yerli ve yabancı turistlerin ilgi odağıdır. Gökova Körfezi, ekolojik tarihi ve doğal yapısı nedeniyle 12.06.1988 tarih ve 88/13109 sayılı Bakanlar Kurulu Kararı ile 05.07.1988 tarih ve 90/1117 sayılı Karar ile "Özel Çevre Koruma Bölgesi (ÖÇKB)" olarak ilan edilmiştir. Bunun yanında, 2008 yılında Akyaka Beldesi'nin "Mavi Bayrak" olarak ilan edilmesiyle belde çevre konusunda daha hassas bir konuma gelmiştir. ÖÇKB olarak kısıtlamalar getirilmiş olan bölgenin ekolojik dengesinin korunması;

Sorumlu Yazar: ata.dadaoz@gmail.com Bu çalışma lisans tez ürünüdür ve TÜBiTAK 2209-Üniversite Öğrencileri Yurt Içi/Yurt Dışı Araştırma Projeleri kapsamında desteklenmiştir.

Geliş Tarihi: 8 Mayıs 2019

Kabul Tarihi: 17 Aralık 2019 
toplum sağlığı, tüm canlı yaşamın sürekliliği ve turizm açısından zorunludur (Kushan ve Yusufoğlu, 2008).

Kadın Azmağı, Gökova'nın kuzeyi ile Akyaka yerleşim alanının kesişim noktasından çıkar. Suyun çıktığı yer beton taş duvarla çevrilmiş ve su belli noktaya kanalize edilmiştir. Çıkış yerinde suyun debisi $700 \mathrm{ls}^{-1,}$ dir. Denize kadar $2 \mathrm{~km}$ uzunluğunda olan Azmak'ta yer yer yoğun bir yosunlaşma olduğu gözlenmektedir. Kadın Azmağı suyunun çıkış noktasında tarımda sulama amaçlı da kullanılmaktadır. Azmağın çıkış noktasından denize doğru gidildikçe debinin de artması ile sadece taşımacılık amaçlı kullanılmaktadır. Kadın Azmağı, doğal bir akvaryum görüntüsü içinde olup, dağlardan gelen tatlısu kaynaklarıyla beslenen bir azmak konumundadır. Kadın Azmağı'nın denizle bağlantısından dolayı anadrom ve katadrom (yılan balığı, kefal, alabalık, çipura ve levrek gibi) balıklara belli devrelerde yaşam alanı sağlamaktadır. Azmakta hayati önem taşıyan ve denize yakın alanda azmağın tabanını kaplayan deniz çayırları (Posidona oceanica) azmağın yaşam kaynağını oluşturan en önemli etmenlerden biridir.

Bu çalışmada Haziran 2012-Mayıs 2013 tarihleri arasında seçilen 5 istasyonda bazı fiziko-kimyasal parametrelerin su analizleri yapılmıştır (Şekil 2; Çizelge 1).

Çizelge 1. Araştırma alanındaki istasyonların koordinatları

\begin{tabular}{lll}
\hline 1 nolu istasyon: Yalıçapkını tabelası yanı. & $37^{\circ} 03^{\prime} 19^{\prime \prime} \mathrm{K}$ & $28^{\circ} 20^{\prime} 17^{\prime \prime} \mathrm{D}$ \\
\hline 2 nolu istasyon: Orfoz restaurant yanı. & $37^{\circ} 03^{\prime} 21^{\prime \prime} \mathrm{K}$ & $28^{\circ} 20^{\prime} 07^{\prime \prime} \mathrm{D}$ \\
3 nolu istasyon: Tatil apart otel önü, Vira Vira restaurant yanı. & $37^{\circ} 03^{\prime} 11^{\prime \prime} \mathrm{K}$ & $28^{\circ} 19^{\prime} 47^{\prime \prime} \mathrm{D}$ \\
4 nolu istasyon: Gökova Körfez Limanı'nda yer alan köprü ayağı. & $37^{\circ} 03^{\prime} 00^{\prime \prime} \mathrm{K}$ & $28^{\circ} 19^{\prime} 39^{\prime \prime} \mathrm{D}$ \\
5 nolu istasyon: Gökova Körfez Limanı. & $37^{\circ} 03^{\prime} 01^{\prime \prime} \mathrm{K}$ & $28^{\circ} 19^{\prime} 31^{\prime \prime} \mathrm{D}$ \\
\hline
\end{tabular}

\section{Örneklerinin Alınması ve Saklanması}

Arazi çalışmalarında istasyonlardan 2 L'lik polietilen şişelerle alınan su numuneleri, dış ortam kaynaklı mikrobiyolojik ve fiziko-kimyasal bozulmalara karşı laboratuara getirilene kadar buzlukta muhafaza edilmiştir. Analizi 1 saatten uzun süren numuneler, laboratuar koşullarında $-20^{\circ} \mathrm{C}^{\prime} \mathrm{de}$ dondurularak saklanmıştır. Seçilen istasyonlarda su sıcaklığı, $\mathrm{pH}$, elektriksel iletkenlik, tuzluluk ve çözünmüş oksijen parametreleri YSI 556 MPS marka (multiparametre ölçer) cihazı ile arazide yerinde ölçümü yapılmış, nitrat azotu, amonyum azotu, orto-fosfat, $\mathrm{BOI}_{5}$ ve klorofil-a analizleri Muğla Sıtkı Koçman Üniversitesi Su Ürünleri Fakültesi Laboratuarı'nda yapılmıştır.

\section{BULGULAR}

Bir yıllık yapılan su kalitesi parametrelerinin analiz sonuçları minimum, maksimum ve ortalama değerleri olarak Çizelge 2'de verilmiştir.

Su sıcaklığı: Yıllık ortalama su sıcaklığı $16.08^{\circ} \mathrm{C}$ ölçülmüş olup, en düşük değer $14.71^{\circ} \mathrm{C}$ ile kış mevsimi 4 . istasyonda,
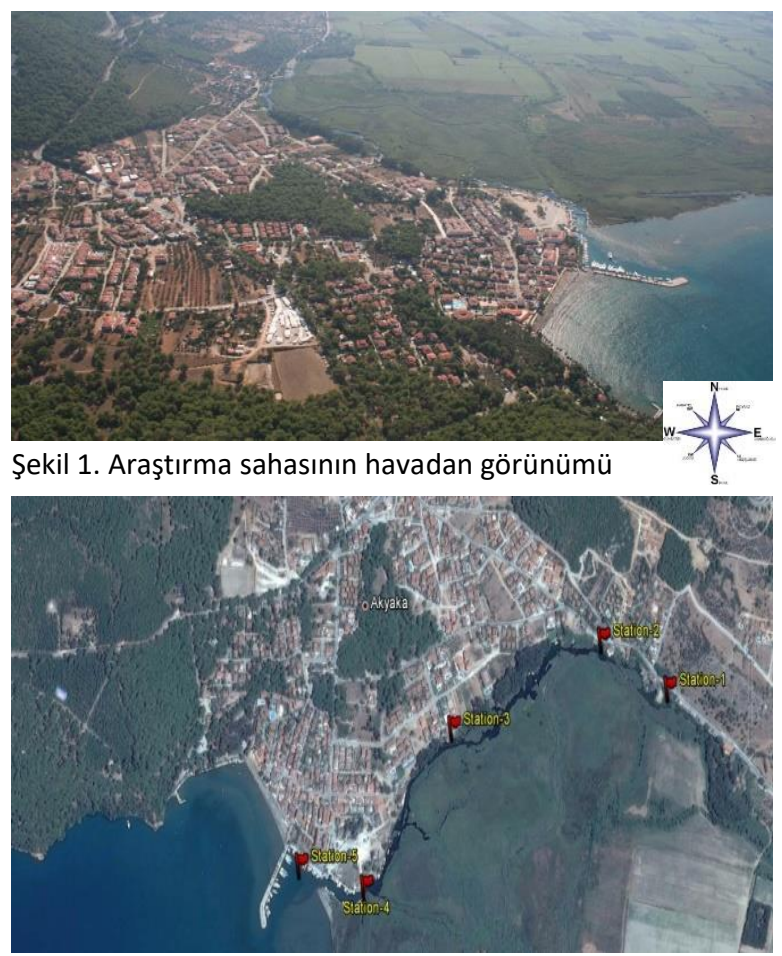

Şekil 2. Araştırma sahasında seçilmiş istasyonlar.

en yüksek yaz mevsiminde $23.12^{\circ} \mathrm{C}$ ile 5 . istasyonda bulunmuştur (Çizelge 2; Şekil 3).

pH: İstasyonlarda belirlenen $\mathrm{pH}$ değerleri 6.70-8.10 arasında değişmekte olup, yıllık ortalama 7.13 olarak tespit edilmiştir. En düşük değer 6.70 ile kış mevsiminde 1. istasyonda, en yüksek değer sonbahar mevsiminde 8.10 ile 5. istasyonda bulunmuştur (Çizelge 2; Şekil 4).

Çözünmüş oksijen: Çözünmüş oksijen değerleri 6.14-8.72 $\mathrm{mgl}^{-1}$ arasında ölçülmüştür. En düşük değer $6.14 \mathrm{mgl}^{-1}$ ile ilkbahar mevsiminde 1 . istasyonda, en yüksek değer yaz mevsiminde $8.72 \mathrm{mgl}^{-1} 4$. istasyonda bulunmuştur (Çizelge 2; Şekil 5).

Biyolojik oksijen ihtiyacı: BOI $_{5}$ değerleri, $0.68-2.52 \mathrm{mgl}^{-1}$ arasında değişmekte olup, ortalama $1.63 \mathrm{mgl}^{-1}$ 'dir. Mevsimsel en düşük $\mathrm{BOI}_{5}$ değeri yazın $0.68 \mathrm{mgl}^{-1}$ ile 2 . istasyonda, en yüksek değer ilkbaharda $2.52 \mathrm{mgl}^{-1}$ ile 4 no'lu istasyonda tespit edilmiştir (Çizelge 2; Şekil 6). 
Çizelge 2. Seçilen istasyonlarda ölçülen bazı fiziko-kimyasal parametrelerin mevsimsel analiz değerleri

\begin{tabular}{|c|c|c|c|c|c|}
\hline İstasyonlar & $\begin{array}{l}1 \\
\text { (Min-Max) }\end{array}$ & $\begin{array}{l}2 \\
\text { (Min-Max) }\end{array}$ & $\begin{array}{l}3 \\
\text { (Min-Max) }\end{array}$ & $\begin{array}{l}4 \\
\text { (Min-Max) }\end{array}$ & $\begin{array}{l}5 \\
\text { (Min-Max) }\end{array}$ \\
\hline Parametreler & Ort. & Ort. & Ort. & Ort. & Ort. \\
\hline \multirow{2}{*}{ Su Sıcaklığı $\left({ }^{\circ} \mathrm{C}\right)$} & $14.86-15.26$ & $15.05-15.54$ & $15.12-15.80$ & $14.71-15.72$ & $15.56-23.12$ \\
\hline & 15.12 & 15.20 & 15.50 & 15.37 & 19.20 \\
\hline \multirow{2}{*}{$\mathrm{pH}$} & $6.70-7.20$ & $6.80-7.00$ & $6.90-7.30$ & $7.00-7.40$ & $7.10-8.10$ \\
\hline & 6.95 & 6.93 & 7.08 & 7.15 & 7.55 \\
\hline Çözünmüş Oksijen & $6.14-7.06$ & $6.15-7.42$ & $7.17-8.37$ & 7.74-8.72 & $6.19-7.27$ \\
\hline$\left(\left.m g\right|^{-1}\right)$ & 6.65 & 6.79 & 7.70 & 8.23 & 6.88 \\
\hline Elektriksel İletkenlik & $5880-7304$ & $3867-11388$ & $5509-6555$ & $5487-6557$ & $32644-46779$ \\
\hline$\left(\mu \mathrm{Scm}{ }^{-1}\right)$ & 6562 & 8824 & 5983 & 5911 & 38684 \\
\hline \multirow[t]{2}{*}{ Tuzluluk (\%o) } & $3.30-4.00$ & $5.50-6.50$ & $3.00-3.60$ & $3.00-3.60$ & $20.90-30.90$ \\
\hline & 3.60 & 6.12 & 3.28 & 3.22 & 24.65 \\
\hline Nitrat Azotu & $2.10-4.73$ & $2.07-4.70$ & $2.03-4.83$ & $2.33-4.83$ & $2.30-5.03$ \\
\hline$\left(\mathrm{NO}_{3}-\mathrm{N} \mathrm{mgl}^{-1}\right)$ & 3.67 & 3.81 & 3.77 & 3.84 & 3.63 \\
\hline Amonyum Azotu & $0.11-0.26$ & $0.26-0.57$ & $0.36-0.56$ & $0.40-0.55$ & $0.78-1.03$ \\
\hline$\left(\mathrm{NH}_{4}-\mathrm{N} \mathrm{mgl}^{-1}\right)$ & 0.16 & 0.44 & 0.46 & 0.47 & 0.86 \\
\hline Orto-fosfat & $0.05-0.17$ & $0.09-0.24$ & $0.04-0.24$ & $0.04-0.27$ & $0.07-0.28$ \\
\hline$\left(\mathrm{PO}_{4}-\mathrm{P} \mathrm{mgl}^{-1}\right)$ & 0.10 & 0.18 & 0.15 & 0.14 & 0.18 \\
\hline \multirow{2}{*}{$\mathrm{BOI}_{5}\left(\mathrm{mgl}^{-1}\right)$} & $0.77-1.51$ & $0.68-1.77$ & $1.76-2.08$ & $1.27-2.52$ & $1.50-2.15$ \\
\hline & 1.15 & 1.21 & 1.94 & 1.99 & 1.85 \\
\hline \multirow{2}{*}{ Klorofil-a $\left(\mathrm{mgl}^{-1}\right)$} & $0.0087-0.0096$ & örnek & $0.0085-0.0098$ & örnek & $0.0089-0.0096$ \\
\hline & 0.0091 & alınmadı & 0.0092 & alınmadı & 0.0092 \\
\hline
\end{tabular}
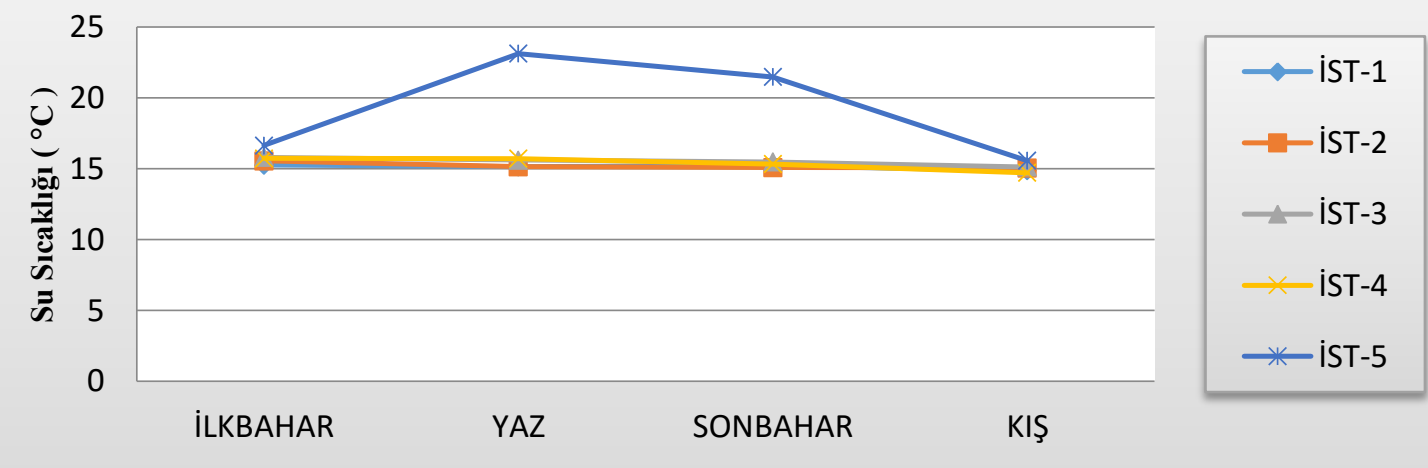

Şekil 3. İstasyonlardaki su sıcaklığının mevsimlere göre değişim grafiği 


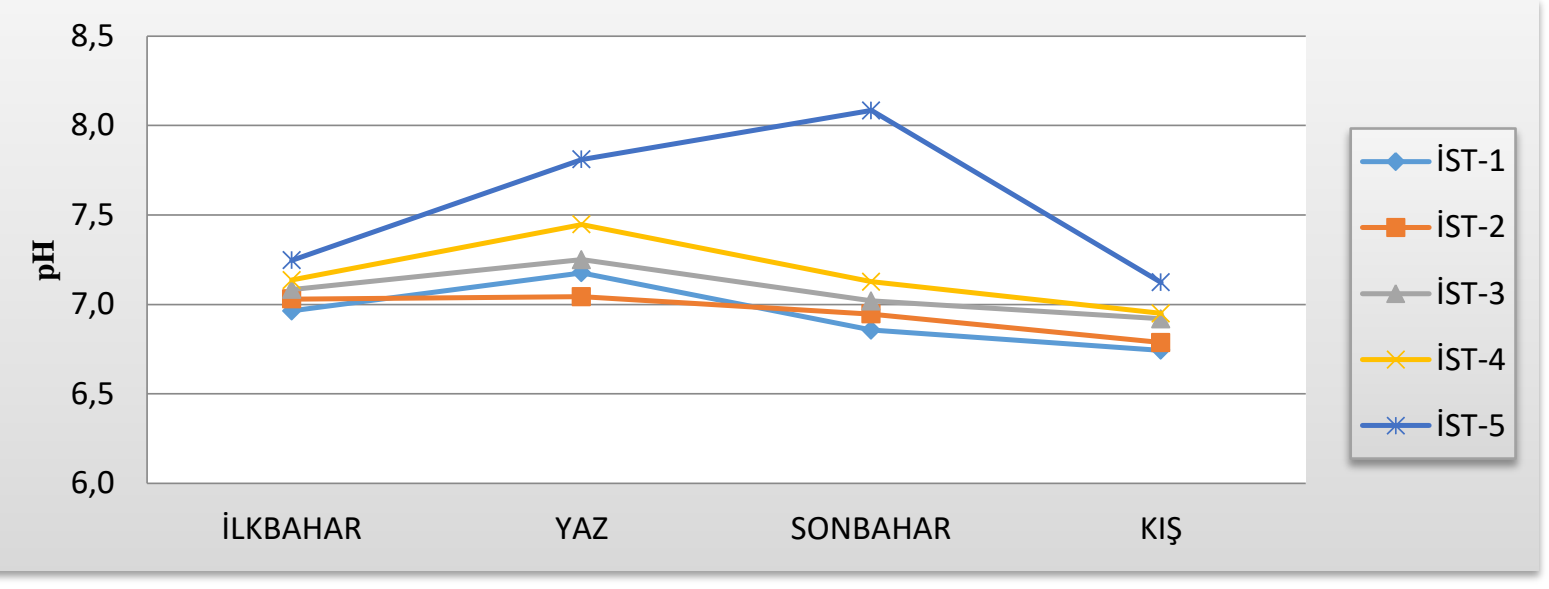

Şekil 4. İstasyonlardaki pH'nın mevsimlere göre değişim grafiği

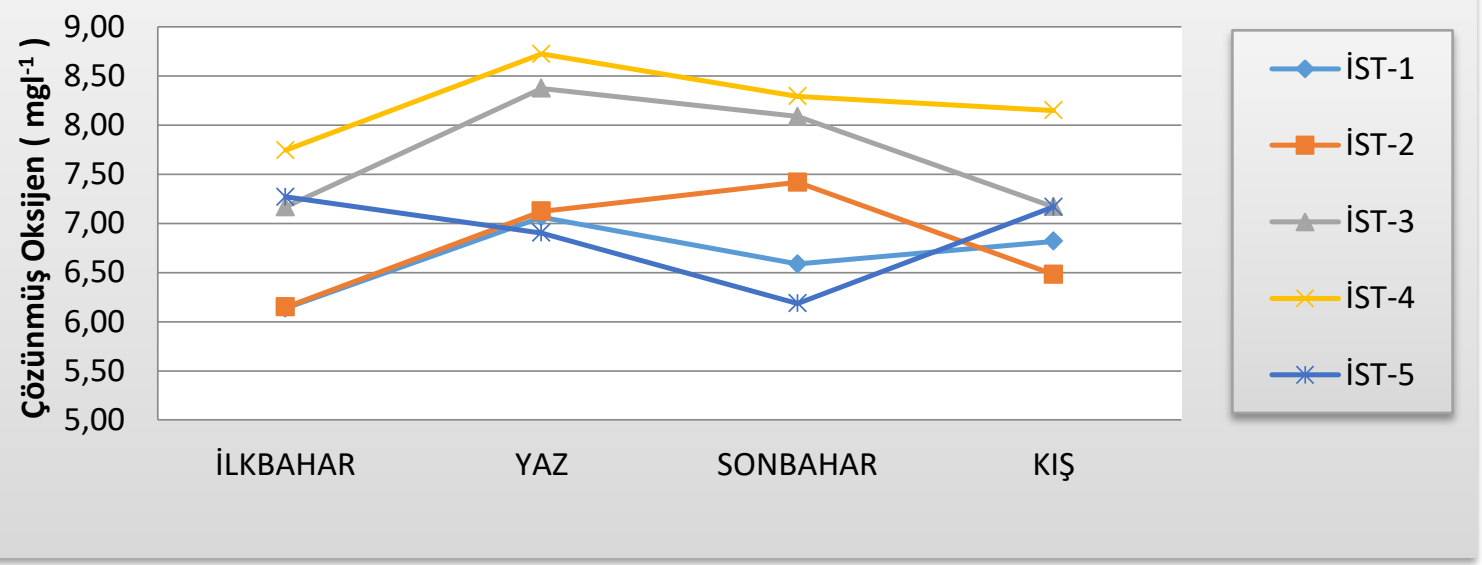

Şekil 5. İstasyonlardaki çözünmüş oksijenin mevsimlere göre değişim grafiği

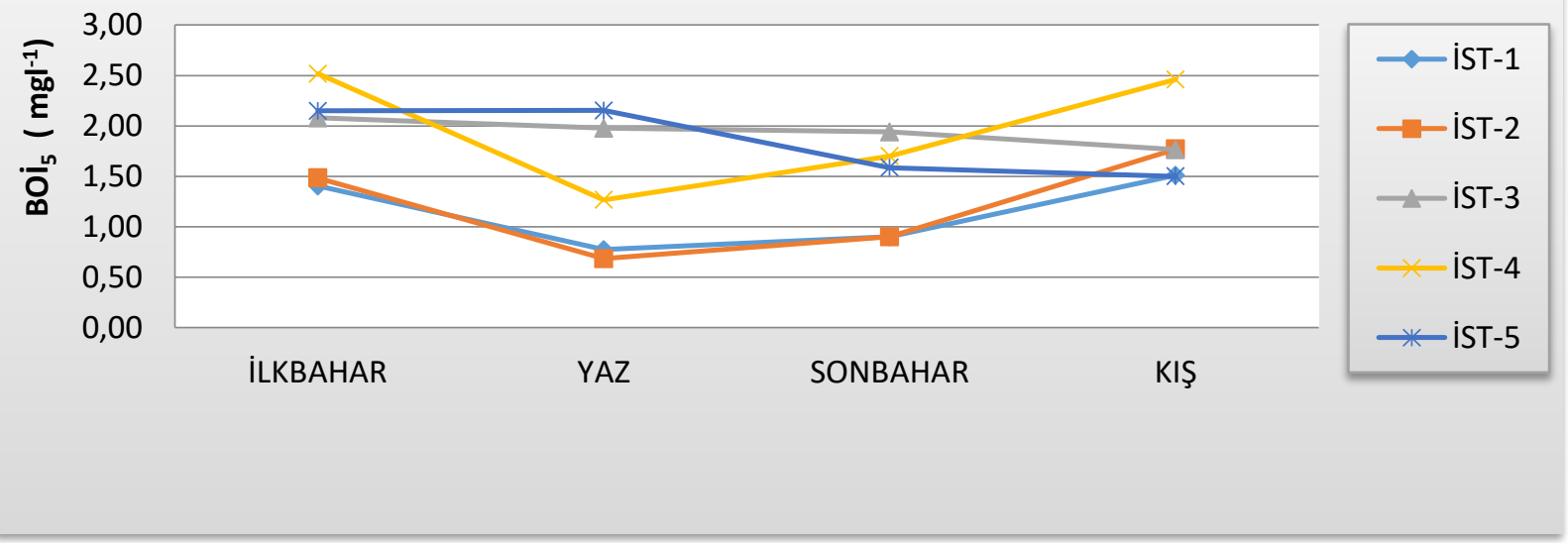

Şekil 6. İstasyonlardaki $\mathrm{BOI}_{5}$ değerlerinin mevsimlere göre değişim grafiği 
Nitrat azotu: Nitrat azotu değerleri bakımından 2.03-5.03 $\mathrm{mgl}^{-1}$ arasında değişmekte olup, yıllık ortalama $3.74 \mathrm{mgl}^{-1}$ olduğu belirlenmiştir. Mevsimsel olarak en düşük ilkbaharda $2.03 \mathrm{mgl}^{-1}$ ile 3 no'lu istasyonda, en yüksek değer ise sonbaharda $5.03 \mathrm{mgl}^{-1}$ ile $5 \mathrm{no}^{\prime}$ lu istasyonda çıkmıştır (Çizelge 2; Şekil 7).

Amonyum azotu: Amonyum azotu değerleri 0.11-1.03 $\mathrm{mgl}^{-1}$ arasında olup, ortalaması $0.48 \mathrm{mgl}^{-1}$ bulunmuştur. Mevsimsel olarak en düşük kışın $0.11 \mathrm{mgl}^{-1}$ ile 1 no'lu istasyonda, en yüksek değer ise kışın $1.03 \mathrm{mgl}^{-1}$ ile $5 \mathrm{no}^{\prime} \mathrm{lu}$ istasyonda tespit edilmiştir (Çizelge 2; Şekil 8).

Orto-fosfat: Orto-fosfat değerleri mevsimsel olarak 0.04 $0.28 \mathrm{mgl}^{-1}$ arasında değişmekte olup, ortalaması $0.15 \mathrm{mgl}^{-}$ ${ }^{1,}$ dir. En düşük değer $0.04 \mathrm{mgl}^{-1}$ ile hem 3. istasyonda sonbahar hem de 4 . istasyonda yaz mevsiminde ölçülmüşken, en yüksek değer $0.28 \mathrm{mgl}^{-1}$ ile $5 \mathrm{no}^{\prime} \mathrm{lu}$ istasyonda kış mevsiminde tespit edilmiştir (Çizelge 2; Şekil 9).

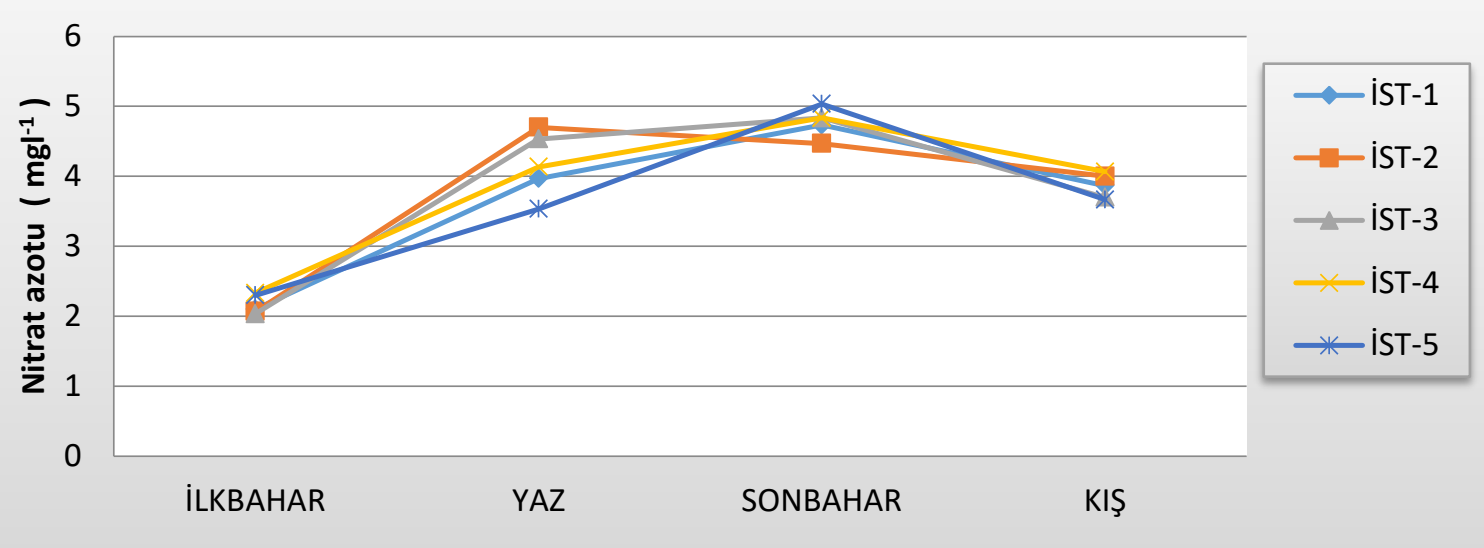

Şekil 7. İstasyonlardaki nitrat azotunun mevsimlere göre değişim grafiği
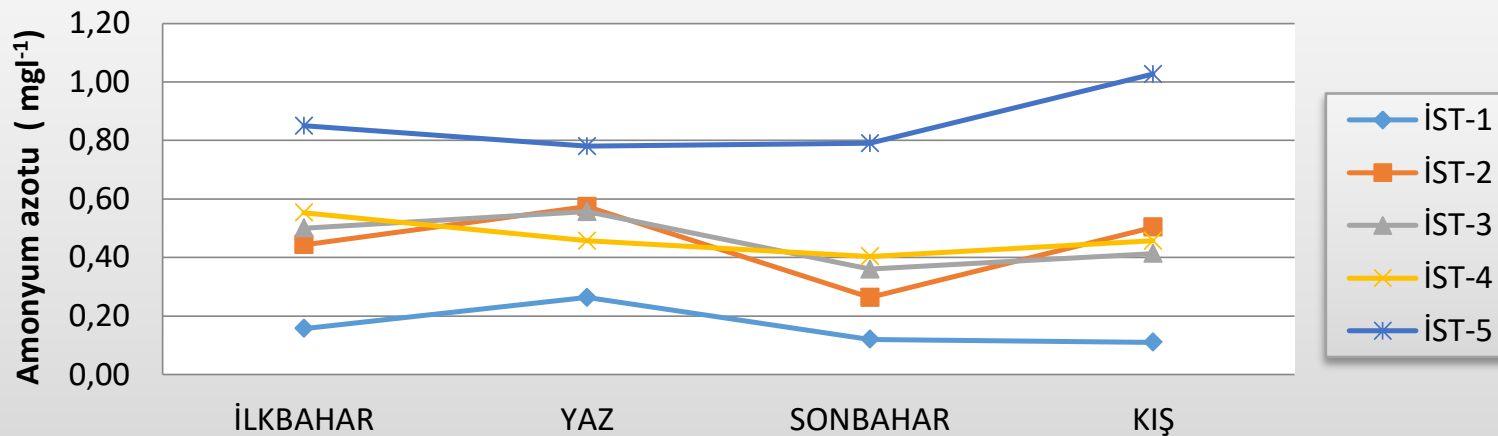

Şekil 8. İstasyonlardaki amonyum azotunun mevsimlere göre değişim grafiği

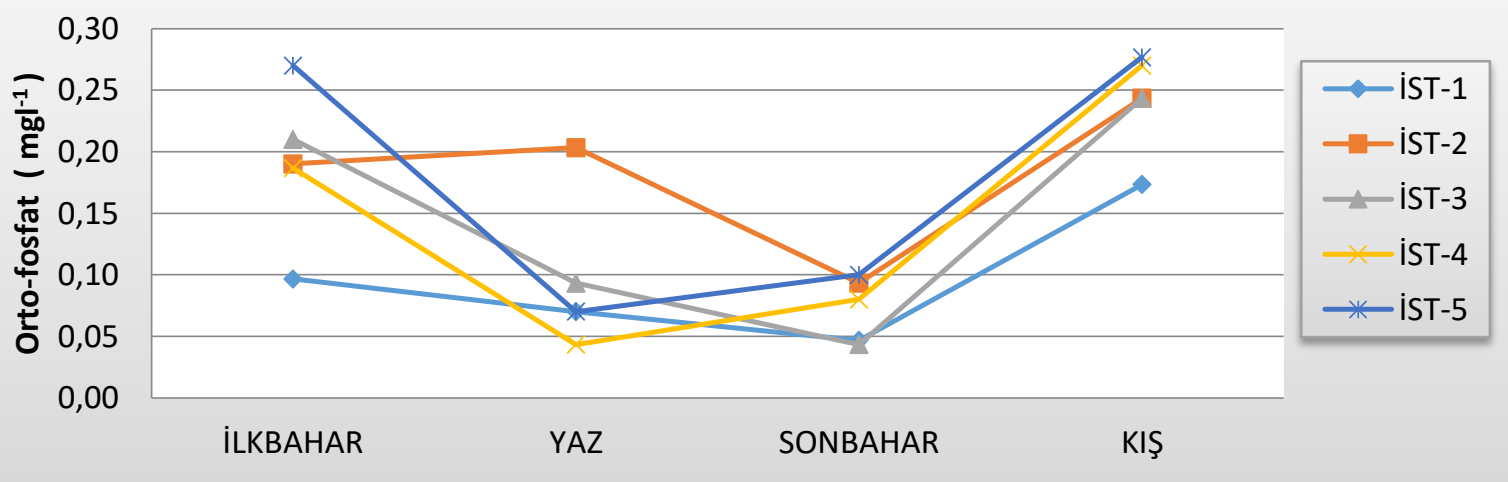

Şekil 9. İstasyonlardaki orto-fosfatın mevsimlere göre değişim grafiği 
Klorofil-a: Klorofil-a bakımından; birinci, üçüncü ve beşinci istasyonlar seçilmiş olup, değerler 0.0085-0.0098 $\mathrm{mgl}^{-1}$ arasında en düşük ve en yüksek değer olarak 3 no'lu istasyonda tespit edilmiştir (Çizelge 2; Şekil 10).
Elektriksel iletkenlik: Elektriksel iletkenlik değerleri 3867$46779 \mu \mathrm{Scm}^{-1}$ arasında değişmekte olup, ortalama olarak $13192 \mu \mathrm{Scm}^{-1}$ ölçülmüştür (Çizelge 2; Şekil 11).

Tuzluluk: İstasyonlarda belirlenen tuzluluk değerleri \%o 3.00-30.90 arasında tespit edilmiştir (Çizelge 2; Şekil 12).

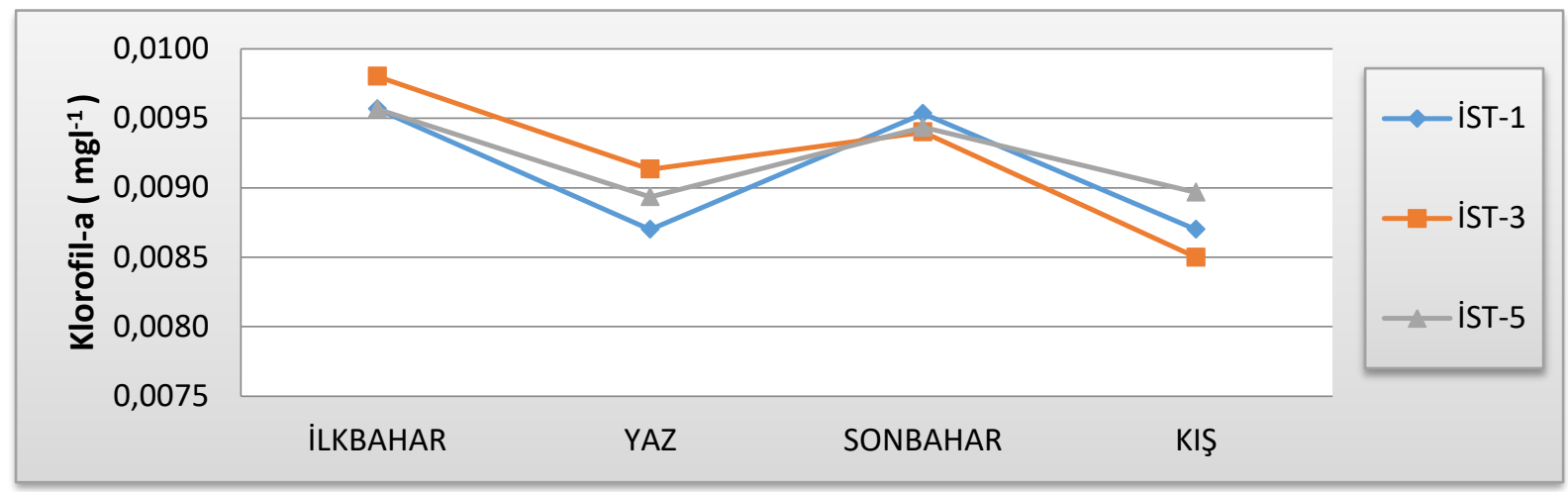

Şekil 10. İstasyonlardaki klorofil-a değerlerinin mevsimlere göre değişim grafiği

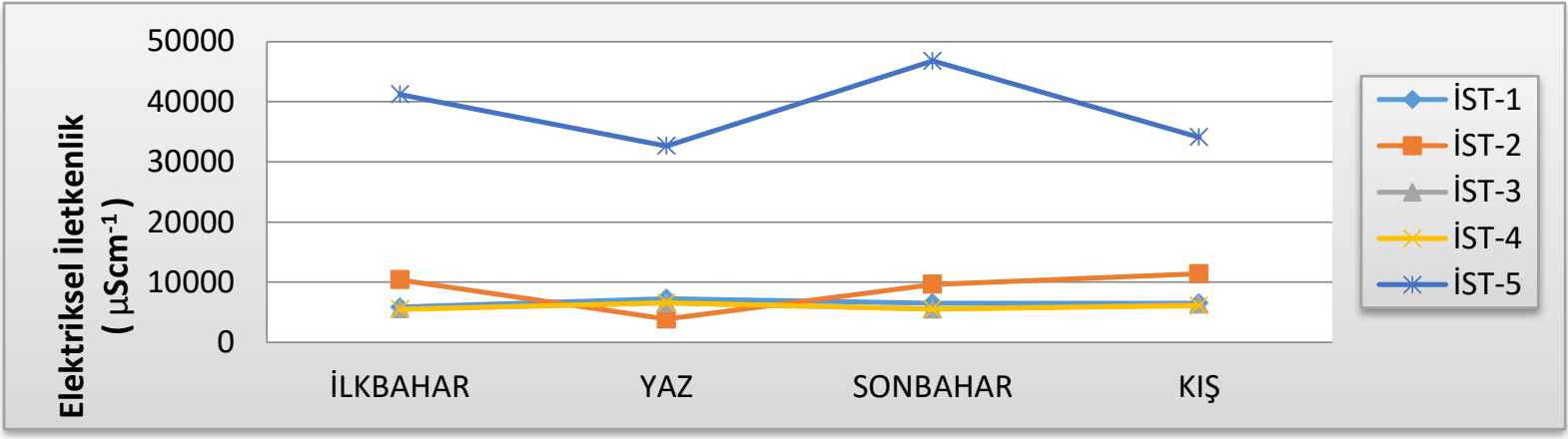

Şekil 11. İstasyonlardaki elektriksel iletkenlik değerlerinin mevsimlere göre değişim grafiği

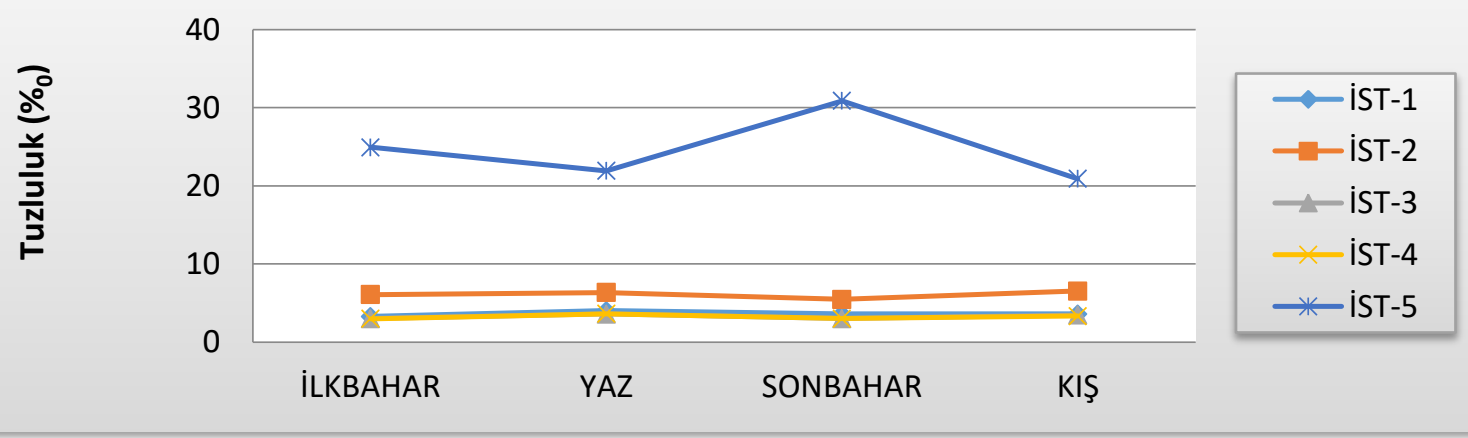

Şekil 12. İstasyonlardaki tuzluluk değerlerinin mevsimlere göre değişim grafiği

\section{Su sıcaklığı-tuzluluk ilişkisi}

Sıcaklık, biyolojik aktivite hızını arttıran oksijen doygunluğunu azaltan önemli bir iklimsel faktördür (Mutluay ve Demirak, 1996; Barlas ve Kiriş, 2004; Cirik ve Cirik, 2005; Mutlu ve ark., 2013). Seçilen istasyonlardaki tuzluluk ve su sıcaklığının (Çizelge 2) düşük seviyelerde görülmesinin nedeni Kadın Azmağı'nın dağlardan gelen tatlı su kaynaklarıyla beslenmesidir. 5 no'lu istasyonda su sıcaklığının ve tuzluluğun artmasının nedeni (Şekil 13) bu istasyonun deniz kısmında, karışım bölgesinde seçilmiş olmasıyla açıklanabilir.

\section{pH-elektriksel iletkenlik ilişkisi}

Suyun asitlik göstergesinden biri olan pH sudaki canlı yaşamını etkileyen önemli bir faktördür. Suyun yüksek pH değeri göstermesi azot bileşiklerinin zararlı etkilerini arttırır (Tanyolaç, 2004; Alam ve ark.., 2007). Elektriksel iletkenliğin yüksek olması ortamdaki tuz seviyesinin yüksek olduğunun belirtisidir (Atay ve Pulatsü, 2000). İstasyonlardaki ortalama değerler birbirine yakın olup (Çizelge 2), ortalamadaki artışın nedeni 5 no'lu istasyondur (Şekil 14). 

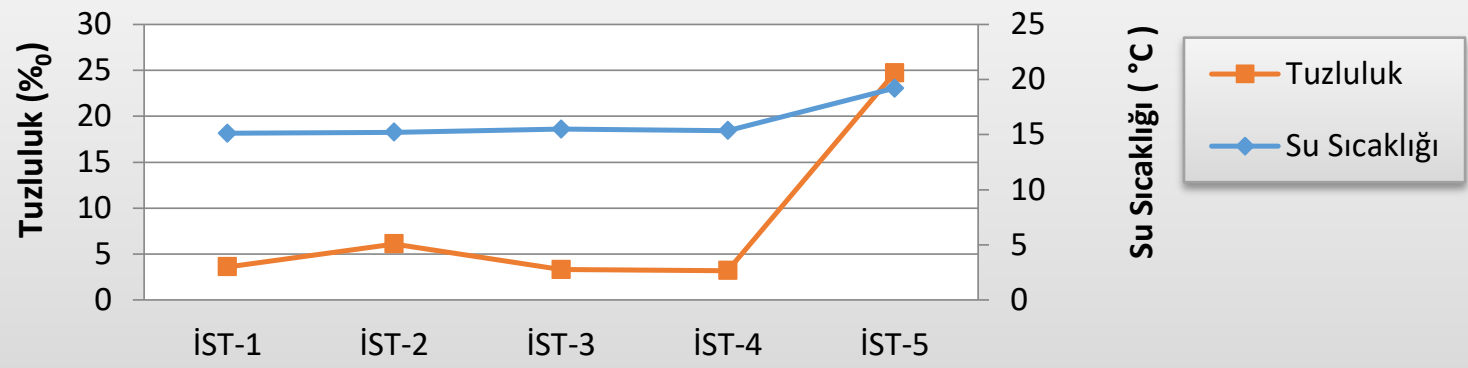

Şekil 13. İstasyonlardaki ortalama su sıcaklığı-tuzluluk ilişkisi

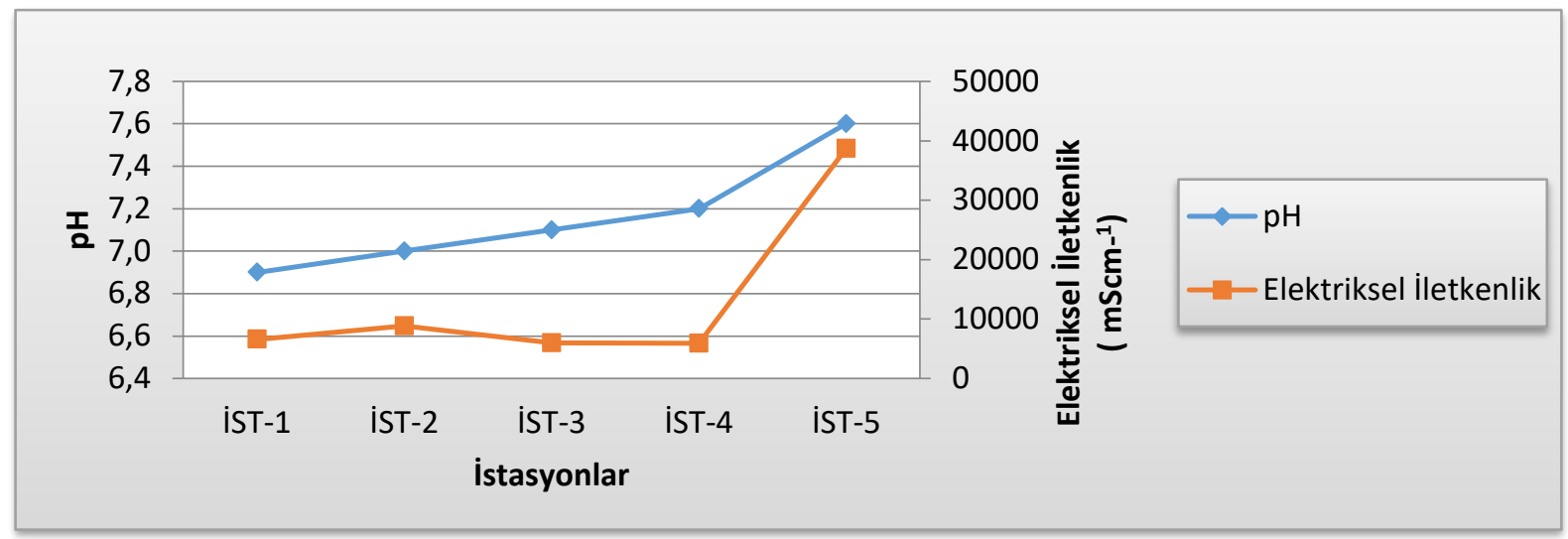

Şekil 14. İstasyonlardaki ortalama pH-elektriksel iletkenlik ilişkisi

\section{Çözünmüş oksijen-su sıcaklığı ilişkisi}

Çözünmüş oksijenin sudaki çözünürlüğü sıcaklık azaldıkça artmaktadır. Sudaki tuz miktarı artarken çözünmüş oksijen miktarı azalmaktadır (Egemen ve Sunlu, 1996; Yanık ve Atamanalp, 2001). İstasyonlardaki çözünmüş oksijen değerleri mevsimsel olarak su sıcaklığına bağlı değişim göstermiştir (Çizelge 2; Şekil 15).

\section{Nitrat azotu-amonyum azotu ilişkisi}

Nitrat azotu alg üremesini sınırlayabilen ve arttırabilen önemli bir faktördür. Fitoplankton gelişimi için vazgeçilmez bir elementtir. Amonyum ise temiz sularda çok az bulunmaktadır. Amonyum sucul canlıların atık maddesi olup, bu canlılar tarafından tekrar absorblanır (Çetinkaya,
2003; Geldiay ve Kocataş, 2005; Barlas, 2011; Tarkan ve ark., 2009). İstasyonlardaki amonyum azotu ve nitrat azotu mevsimsel turizm faaliyetlerine bağlı olarak yaz aylarında artışlar gösterip kış aylarında genelde düşüşler göstermiştir (Çizelge 2; Şekil 16).

\section{Su sıcaklığı-klorofil-a ilişkisi}

Yaz aylarındaki sıcaklık artışına bağlı olarak istasyonlardaki su sıcaklığında artışlar görülmektedir. Bu su sıcaklığının artışı ile sucul ortamdaki besin tuzlarının etkileşimiyle hareketlilikler görülmektedir (Munsuz ve Ünver, 1995). İstasyonlardaki klorofil-a değerleri (Çizelge 2; Şekil 17) sıcaklığa, güneş ışığına ve besleyici elementlere bağlı olarak hareket göstermektedir (Çiçek ve Ertan, 2012).

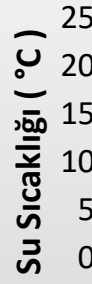

$$
\left.\begin{array}{l}
25 \\
20 \\
15 \\
10 \\
5 \\
0
\end{array}\right]
$$
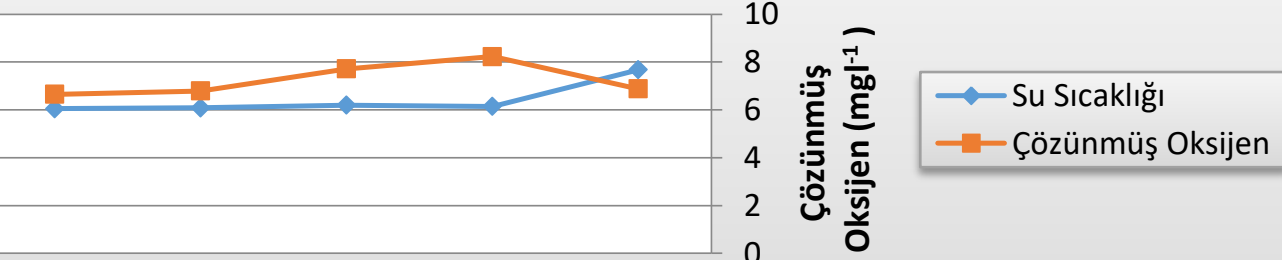

$$
\text { iST-1 iST-2 iST-3 iST-4 iST-5 }
$$

Şekil 15. İstasyonlardaki ortalama su sıcaklığı-çözünmüş oksijen ilişkisi 


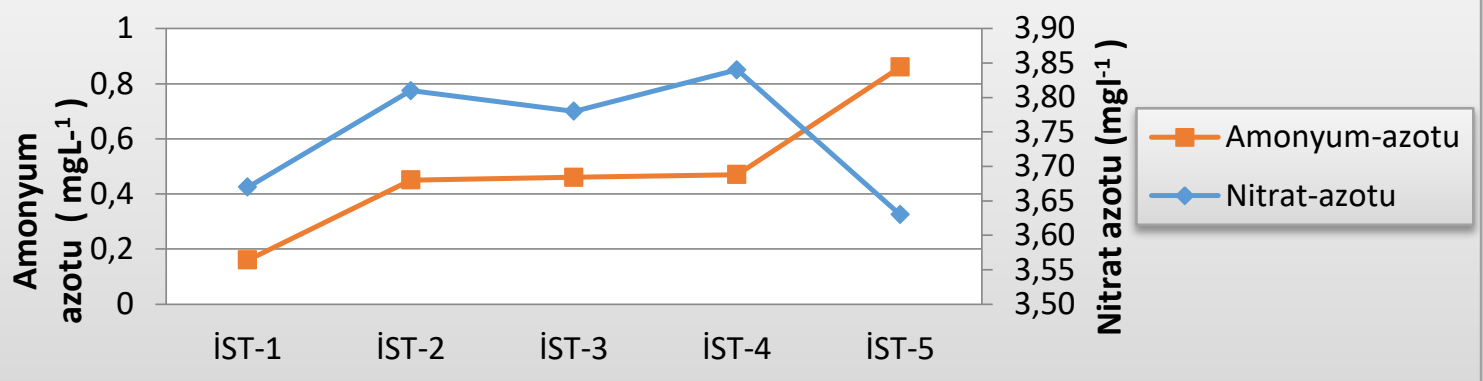

Şekil 16. İstasyonlardaki amonyum azotu-nitrat azotu ilişkisi
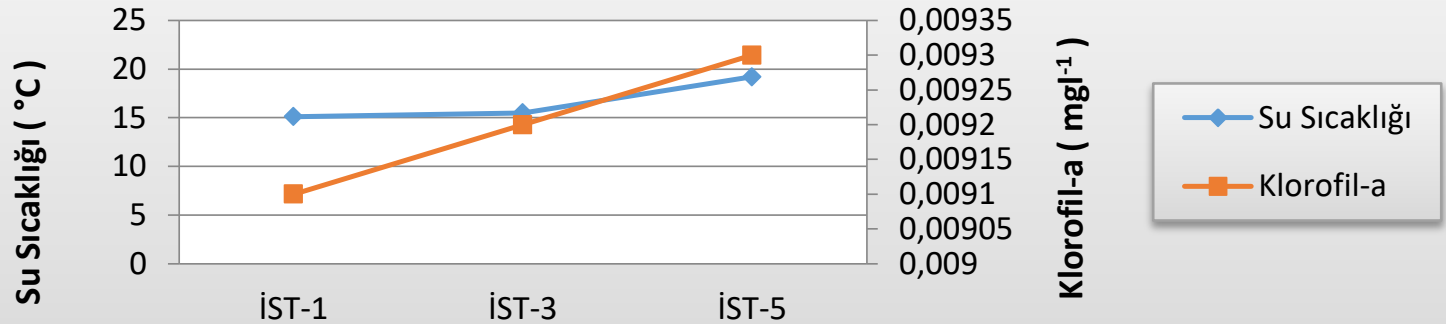

Şekil 17. İstasyonlardaki ortalama su sıcaklığı-klorofil-a ilişkisi

\section{TARTIŞMA VE SONUÇ}

2008 ve 2009 yıllarında Kadın Azmağı'nda mevsimsel yapılan su kalitesi çalışmalarındaki (Çizelge 4) istasyonlar dikkate alınarak bu çalışmadaki istasyonlarla aynı noktalardan seçilmesine özellikle dikkat edilmiştir. Böylece bu çalışmada elde edilen su analiz sonuçlarının yıllar bazında bilimsel karşılaştırılması yapılmıştır. Su Kalitesi Kontrolü Yönetmeliğine (SKKY, 2008)' göre de su kalitesi sınıfları Çizelge 5'de verilmiştir. Bazı su kalite parametreleri Çizelge 4. Kadın Azmağı'ndaki çalışmanın geçmiş yıllarda yapılan çalışmalarla karşılaştırılması

\begin{tabular}{|c|c|c|c|c|}
\hline Parametreler & $\begin{array}{l}\text { Kalyoncu ve ark., } \\
(2008)\end{array}$ & $\begin{array}{l}\text { Tarkan ve } \\
(2009)\end{array}$ & ark., & $\begin{array}{l}\text { Yapılan bu çalışmada (2012- } \\
\text { 2013) }\end{array}$ \\
\hline Su Sıcaklığı $\left({ }^{\circ} \mathrm{C}\right)$ & 16.40 & 16.48 & & 16.08 \\
\hline $\mathrm{pH}$ & 7.50 & 6.68 & & 7.13 \\
\hline Çözünmüş oksijen $\left(\mathrm{mgl}^{-1}\right)$ & 6.01 & 8.94 & & 7.25 \\
\hline Elektriksel iletkenlik $\left(\mu \mathrm{Scm}^{-1}\right)$ & 6500 & 9309 & & 13193 \\
\hline Tuzluluk (\%o) & 3.75 & 5.38 & & 8.17 \\
\hline Nitrat azotu (mgl $\left.{ }^{-1}\right)$ & $10.5-23.8$ & 5.40 & & 3.70 \\
\hline Amonyum azotu $\left(\mathrm{mgl}^{-1}\right)$ & $1.96-2.52$ & 1.93 & & 0.48 \\
\hline Orto-fosfat $\left(\left.m g\right|^{-1}\right)$ & $0.064-0.096$ & 2.22 & & 0.15 \\
\hline
\end{tabular}
oksijen açısından paralellik gösterirken, elektriksel iletkenlik, tuzluluk, nitrat azotu, amonyum azatu ve ortofosfat değerleri bakımından farklılıklar olduğu görülmektedir. Bu farklılıkların nedenleri olarak yıllar bazında ikincil konutların artması, yaz aylarında artan turizm faaliyetleri gibi çevresel faktörler olduğu düşünülmektedir.
Çizelge 4'e göre kıyaslandığında; Su sıcaklığı, pH, çözünmüş 
Çizelge 5. Su kalitesi kontrol yönetmeliğine göre istasyonların su kalite sınıfları.

\begin{tabular}{|c|c|c|c|c|c|}
\hline $\begin{array}{l}\text { İstasyonlar } \\
\text { Parametreler }\end{array}$ & 1 & 2 & 3 & 4 & 5 \\
\hline Su Sıcaklığı $\left({ }^{\circ} \mathrm{C}\right)$ & 1 & 1 & 1 & 1 & 1 \\
\hline $\mathrm{pH}$ & I & I & 1 & 1 & I \\
\hline $\begin{array}{l}\text { Çözünmüş Oksijen } \\
\left(\mathrm{mgl}^{-1}\right)\end{array}$ & $|-| \mid$ & $|-| \mid$ & I & I & I-II \\
\hline $\begin{array}{l}\text { Nitrat Azotu } \\
\left(\mathrm{NO}_{3}-\mathrm{N} \mathrm{mgl}^{-1}\right)\end{array}$ & 1 & 1 & I & 1 & I \\
\hline $\begin{array}{l}\text { Amonyum Azotu } \\
\left(\mathrm{NH}_{4}-\left.\mathrm{N} \mathrm{mgl}\right|^{-1}\right)\end{array}$ & III & II-III & II-III & II-III & IV \\
\hline $\begin{array}{l}\text { Orto-fosfat } \\
\left(\mathrm{PO}_{4}-\mathrm{P} \mathrm{mgl}^{-1}\right)\end{array}$ & II-III & II-III & II-III & II-III & II-III \\
\hline $\mathrm{BOI}_{5}\left(\mathrm{mgl}^{-1}\right)$ & I & I & I & I & 1 \\
\hline
\end{tabular}

Kış nüfusu yaklaşık 2000 civarında iken bu sayı turizm sezonunda günlük ortalama 10000-15000 kişiye ulaşmakta olup, bu da beldeye ciddi bir yoğunluk getirmektedir. Turizm sezonun başlamasıyla seçilen istasyonlarda yaptığımız su analizleri sonucunda özellikle amonyum azotu ve orto-fosfat değerlerinde sezona bağlı olarak artışlar gözlenmiştir. Yaz sezonunda günlük tur teknelerinin özellikle hafta sonları önemli oranda sefer sayı artışı dikkati çekmiştir.

2008 yılında araştırma sahasının "Mavi Bayrak" olarak ilan edilmesiyle belde daha da hassas bir konuma gelmiştir. Özellikle hafta sonlarında yaşanan yoğun turistik aktiviteden özellikle Akyaka Beldesi ve kıyı bandı çevre kirliliği açısından olumsuz etkilendiği görülmüştür. Bu açıdan bakıldığında beldenin Mavi Bayrak konumunun tehlikeye gireceği açıktır. Turizm sezonunda, bir sınırlama getirilmeden 20-30 kişilik tur teknelerinin gün boyunca gezintileri Kadın Azmağı kenarındaki flora ve fauna için olumsuz bir tehlike oluşturmaktadır. Çoğu zamanda tur tekneleri kapasite üzerinde yolcu almakta olup, buda teknelerin motor gücünü zorlamaktadır. Bu tur gezintilerinde herhangi bir düzen olmadan, müşteri olduğu sürece turlar gün içinde devam etmektedir. Halbuki teknelerin motor tipleri azmak için uygun olmayıp, teknelerin pervanelerine takılan su bitkileri özellikle dip yapıdaki Posidonia oceanica için tehlikeler oluşturabilmektedirler. Bunun yanında sazlıklar arasındaki kuş yuvaları ve yumurtaları, anadrom ve katadrom balıklar için de olumsuz etkileri vardır.

Kadın Azmağı'nın doğal akvaryum görüntüsünün korunması ve uzun ömürlü olması için tekne trafiğine bir düzen içinde izin verilmelidir. Kadın Azmağı boyunca demir atmış teknelere ise Akyaka Belediyesi tarafından alternatif bir park yapma yeri önerilmelidir. Bu tedbirler acilen alınmazsa, yakın bir gelecekte azmaktaki flora ve faunanın yok olması gündeme gelebilir. Kadın Azmağı'nın çıktığı kaynağın civarında az da olsa bir tarımsal faaliyet mevcut olup, bu durum pestisit ve gübre kirliliğini de beraberinde getirebilir.
Gökova Körfezi'ni besleyen azmakların su kalitesi izleme (monitoring) olarak çalışılmalıdır.

Tur teknelerinin sintine sularının toplanacağı bir sintine toplama tankının acilen aktif hale getirilmesi önemlidir.

Kadın Azmağı boyunca yer alan dokuz restaurantın kullandığı atık yağların haftada en az bir defa olmak üzere Akyaka Belediyesi tarafından toplanması ve çalışan personelin çevre eğitimi almaları gerekmektedir. Bunun yanında mevcut restaurant sayısının korunarak yenilerinin açılmasına izin verilmemesi de önemlidir.

Özel Çevre Koruma Bölgesi olmasına rağmen araştırma sahasında yaptığımız çalışmalar sonucunda bilimsel anlamda çevresel kirlenmeler tespit edilmiştir. Araştırma sahasının geleceği açısından gerekli tüm tedbirlerin ilgili resmi kurumlar, belediyeler, muhtarlıklar ve sivil toplum örgütleriyle ortak bir payda altında alınması önemlidir.

\section{Teşekkür}

Bu çalışma, TÜBiTAK 2209-Üniversite Öğrencileri Yurt İçi/Yurt Dışı Araştırma Projeleri tarafından desteklenmiştir. Desteklerinden dolayı TÜBiTAK'a teşekkür ederiz.

\section{KAYNAKLAR}

Alam MJB, Islam MR, Muyen Z, Mamun M, Islam S (2007) Water Quality Parameters Along Rivers. Int. J. Environ. Sci.Technol 4:159-167.

Atay D, Pulatsü S (2000) Su Kirlenmesi ve Kontrolü, Ankara Üniversitesi Basımevi, Ankara, 307.

Barlas M (2011) Su Kalitesi Tayin Yöntemleri, Yüksek Lisans Ders Notları, Muğla, 39.

Barlas M, Kiriş E. (2004) Akçay (Muğla-Denizli)'ın Fizikokimyasal ve Bentik Makroinvertebrata Yönünden Incelenmesi, Muğla Üniversitesi Yayınları: 49.

Cirik S, Cirik, Ş (2005) Limnoloji Ders Kitabı, Ege Üniversitesi Su Ürünleri Fakültesi Yayınları, İzmir, No:21, Yayın No:5, 166.

Çetinkaya O (2003) Su Kalitesi Ders Notları, Yüzüncü Yıl Üniversitesi Ziraat Fakültesi Su Ürünleri Bölümü. Van, 76. 
Çiçek NL, Ertan ÖO (2012) Köprüçay Nehri (Antalya)'nin Fiziko-kimyasal Özelliklerine Göre Su Kalitesinin Belirlenmesi. Ekoloji Dergisi 21(84):54- 65.

Egemen Ö, Sunlu U (1996) Su Kalitesi Ders Kitabı, Ege Üniversitesi Yayınevi, İzmir, 153.

Geldiay R, Kocataş A (2005) Deniz Biyolojisine Giriş (Ders Kitabı), 5. Baskı, Ege Üniversitesi Basımevi, İzmir, 614.

Gündoğdu V, Özkan EY (2006) Küçük Menderes Nehri Ölçüm Ağı Tasarımı ve Su Kalite Değişkenlerinin İrdelenmesi Çalışması, E.Ü. Su Ürünleri Dergisi, 23, (34): 361-369.

Kalyoncu H, Barlas M, Yıldırım MZ, Yorulmaz B (2008) Gökova Körfezi (Muğla, Türkiye)'nin Önemli Akarsuyunun Gastropodları ve Su Kalitesi ile Ilişkisi. International Journal of Science \& Technology. Sayı: 3, No: 1, 27-36.

Kushan D, Yusufoğlu A (2008) Gökova Özel Çevre Koruma Bölgesi. Türkiye Kıyıları'08 Kongresi Bildiriler Kitabı, Ankara, 532.
Munsuz, N, Ünver i (1995) Su Kalitesi, Ankara Üniversitesi, Ziraat Fakültesi, 460.

Mutlu E, Yanık T, Demir T (2013) Horohon Deresi (HafikSivas) Su Kalitesi Özelliklerinin Aylık Değişimleri. Alınteri Zirai Bilimler Dergisi, 25(2), 45-57.

Mutluay H, Demirak A (1996) Su Kimyası, Beta Basımevi, İstanbul, 135.

Tarkan AN, Özdemir N, Demirak A, Filiz H, Tarkan AS, Bilge G, Gülşahin N, Yavuz E, Boran R, Özel I, Yılmaz H, Erdinç ÖS (2009) Gökova İç Körfezi'nde Su Kalitesi ve Denizel Biyoçeşitlilik. Muğla Üniversitesi Baskısı, SMAP III Gökova Projesi, 6-12.

Tanyolaç J (2004) Limnoloji (3. Baskı). Ankara: Hatipoğlu Yayınevi, 237.

SKKY (2008) T.C. Resmi Gazete, Su Kalite Kontrol Yönetmeliği, 26786-13.2.2008.

Yanık T, Atamanalp M (2001) Balık Yetiştiriciliğinde Su Kirliliğine Giriş. Ankara Üniversitesi, Ziraat Fakültesi Ders Yayınları No:226, Erzurum, 322. 